\title{
Numerical Simulation of Rotary Compression Process of Hollow Balls
}

\author{
D. Skrochocki ${ }^{1}$ and J. Tomczak ${ }^{2}$ \\ Politechnika Lubelska, Lublin, Poland \\ 1 skrochocki@gmail.com \\ 2 j.tomczak@pollub.pl
}

This paper presents results of the analysis of numerical Simulation of rotary compression process of hollow ball forging. Numerical analysis is conducted based on the finite element method using the Simufact Forming software. The methods of hollow ball forming are discussed with presentation of the geometrical model applied in calculations and the obtained rotary compression process description. The simulation is conducted under three-dimensional strain conditions. Strain, stress and temperature distributions are determined. The diagrams of forces and rotary moments of the hollow forging compression process are given. The described results of the numerical analysis confirm the possibility of producing the hollow balls by means of rotary compression with the use of billet in the form of a pipe part.

Keywords: rotary compression, hollow ball, finite element method (FEM).

Introduction. A large interest has been recently shown for hollow elements used in industry, particularly in automotive and aviation fields. These elements fulfill the requirements of their equivalents with a smaller mass, which considerably increases the machine capabilities and concurrently improves their dynamics, as well as reduces their fuel consumption. Axles and shafts, including toothed ones, are the largest group of machines subassemblies, in which hollow elements replace their equivalents [1, 2]. However, it should be noted that hollow products are used not only in automotive or aviation industry. There are hollow elements that are widely applied in the industrial hydraulics (force, water or sanitary), for instance in the form of ball valve balls.

In the middle of the XX century, only poppet valves and wedge bolts were used in industrial systems. The tightness of such valves was inadequate, which made the valve manufacturers search for new solutions. The first ball valve was invented by Hubert Klinger-Lohr and patented in 1957. The valve design underwent multiple modifications to obtain the standard. The ball valves in units and systems are mainly used as flow separation elements. Seldomly they are used as flow restrictor elements or elements controlling the flow value. Hence, it is important to have the valve with the maximum level of efficiency to provide both its reliable application and safe operation of the system as well as safety of the personnel responsible for the system maintenance. To ensure obtaining of the assumed efficiency and failure free operation of the ball valve, the ball is required to be produced from solid materials.

The most popular and the simplest method of hollow balls production is machining. However, the use of this technology is related with the considerable material loss up to $75 \%$ of the billet. Therefore, it is crucial to find more optimal methods of hollow balls production. Many known methods of producing full balls by metal technology are used nowadays. The most popular one involves die forging on press, die forging on screw press, cross wedge rolling and rolling on skew rolling machines [3, 4]. However, all the mentioned methods of ball production relate to full forging with a relatively small diameter. There still remains the problem of material consumption connected with the operation of port hole production. 
In case of ball valves, the material loss due to hole drilling varies within the range of up to $50 \%$. Therefore, it is necessary to find more material consuming and optimal methods of ball hollow production. One of the solutions to this problem is the two-stage forging of the hollow ball from the bush or the pipe part in dies split by the punch [5]. The method of hollow balls forging in split dies requires the use of the special technological device due to kinematics assumptions, which impose some technological limitations. Some part of the steel pipe can be deformed using traditional die forging technique in tools of ball die impression [6]. Therefore, the ball with a spherical hole is obtained. In order to obtain the cylindrical hole along the entire length, it is required to fix the part of the pipe or the bush inseparably. An identical hollow ball can be obtained using such a relatively new method of manufacturing of axially symmetrical thin-walled specimens, as hydroforming [7], which is applicable for the production of thin-walled elements. Their formation using the processes of extrusion, spinning, roll flowing or bending is found to be a very difficult task. Hydroforming technology for hollow balls manufacturing from semi-finished products of the pipe type [8] makes it possible to obtain the products identical to those produced by forging from the pipe part. The disadvantage of this method, as in case of forging, lies in the formation of ball-shaped specimens with a spherical hole.

One of the new methods of metal forming of hollow products is the rotary compression. This technology has been developed at the Department of Computer Modeling and Metal Forming of the Lublin University of Technology, where advanced investigations are conducted using the process of rotary forming. Rotary compression is based on the formation of products by three identical shaped rolls placed at the angle of $120^{\circ}$ relative to each other (on the semi-finished product circumference). The tools rotate in the same direction and perform the translational motion in the semi-finished product axis direction. The billet in the form of a pipe or a bush part is placed between the rolls, which during the rotary compression process make their imprint in it. The obtained results of investigations on the rotary compression technology of axes, shafts and machine parts with more complex geometry compared with the that one of the hollow ball pin, the toothed shaft $[9,10]$ and the shaft with a winding worm [11] justify the continuation of investigations on the rotary compression for hollow products' manufacturing.

Experimental. The analysis of rotary compression of the hollow balls is conducted using a ball valve specimen of hollow ball that is used by one of the leading manufacturers. The quadruple serial system of balls arrangement is used due to the size of the chosen hollow ball (Fig.1). Hence, the rotary compression makes it possible to produce the specimen to obtain four finished products. The hollow balls are placed in a such way that their separation is possible after rotary compression process (at the point of the smallest forging diameter) with tolerance for machining.

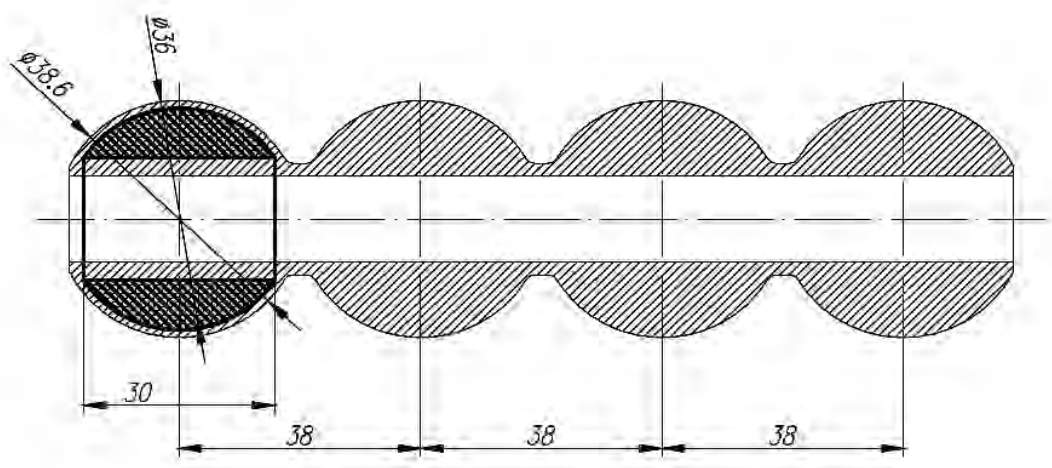

Fig. 1. Shape and chosen dimensions of hollow ball specimens. 
The numerical analysis of the rotary compression of hollow ball forgings is made using FEM with the Simufact Forming software. Figure 2 illustrates the geometrical model of the process used in the current analysis. This model consists of three shaped rolls-tools, the billet in the form of a pipe and mandrel. Tools $(1,2,3)$ rotate with a constant velocity $n=36 \mathrm{rpm}$ in the same direction and perform radial motion with velocity $v=2 \mathrm{~mm} / \mathrm{s}$ along the semi-finished product axes. The translational motion of rolls takes about $80 \%$ of the rotary compression process, while rotation of the remaining $20 \%$ of tools occurs only when sizing the sample with a simultaneous removal of the geometrical inaccuracy of forgings (6). The semi-finished product that undergoes machining is a pipe (4) of C45 steel with an external diameter $D=38 \mathrm{~mm}$, wall thickness $g=6 \mathrm{~mm}$, and length $L=140 \mathrm{~mm}$. The semi-finished product is modeled using the hexahedral elements. The material data on C45 steel are obtained from Simufact Forming library. It is assumed that the billet is heated along its entire volume to the temperature of $1150^{\circ} \mathrm{C}$, while the tool temperature is $100^{\circ} \mathrm{C}$. The heat exchange coefficient between the semi-finished product and the tool is assumed to be $20 \mathrm{~kW} /\left(\mathrm{m}^{2} \cdot \mathrm{K}\right)$. At the area contact between the material and the tool the limiting value of friction factor is $m=1$. However, at the contact between the material and the mandrel the friction factor is $m=0.3$.

In order to obtain the most accurate form of the sample hole and concurrently to limit the material flow in the axial direction, the mandrel was placed into the semi-finished product axis (5). To simplify the analysis, the mandrel performs only a single free step, which implies that it can freely rotate around its axis.

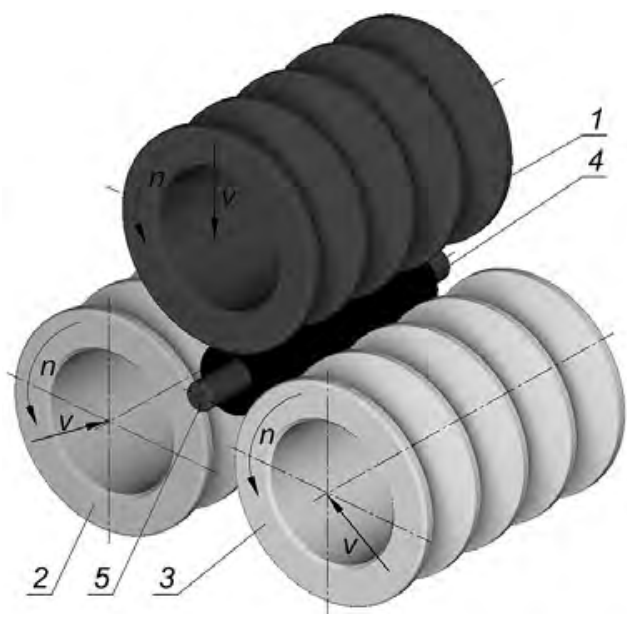

a

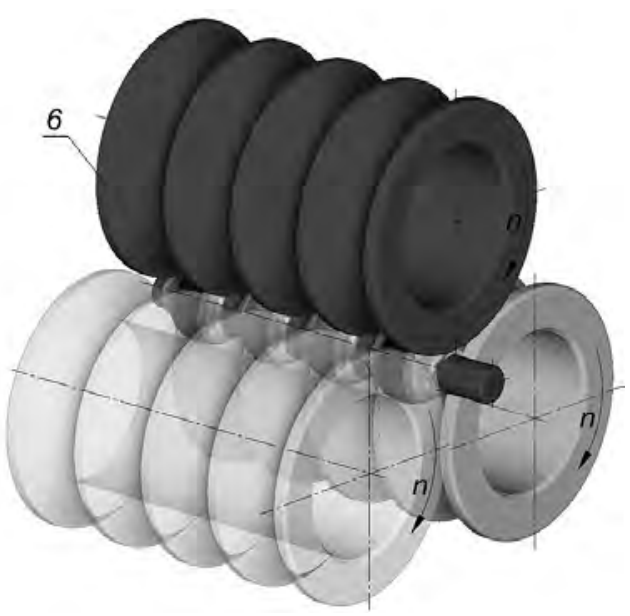

b

Fig. 2. Scheme of the rotary compression process of hollow ball specimens: (a) the beginning of the process; (b) the end of the process (description of the symbols is given in the text.)

Results and Discussion. The results of the performed numerical calculations make it possible to analyze the shape variation of hollow ball specimens during the rotary compression process (Fig. 3). During the process, the gradual reduction of the billet diameter takes place in the areas with bridges connecting the specified balls. The material flow observed between them is more intensive in the radial direction other than in the axial one. It is beneficial since the obtained material is closed between the tools forming the impressions. After about one third time of the process, the obtained material is in contact with the mandrel and undergoes rotation due to friction. Dynamics of the obtained material displacement increases in the radial direction together with the roll translational motion. The radial direction of the material flow is dominant, which leads to the formation of the 


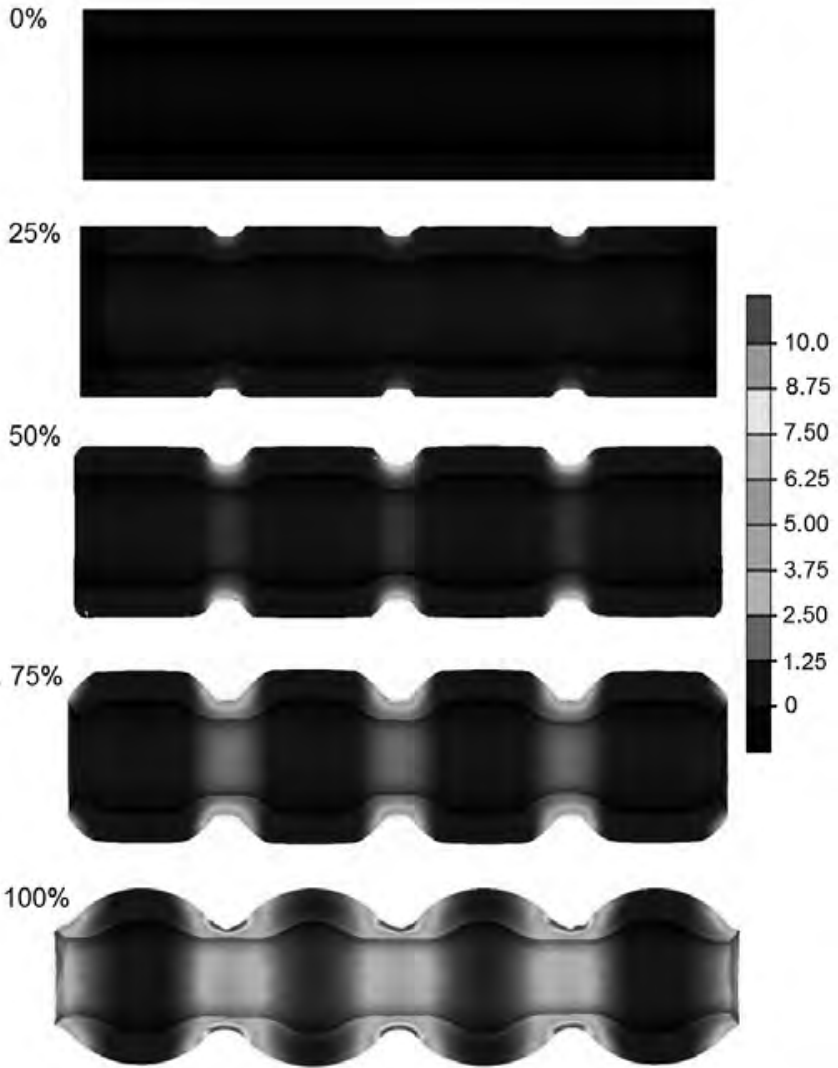

Fig. 3. Shape variation of the hollow specimen in the rotary compression process with the specified strain intensity.

forging external spherical surfaces, where the material excess is observed due to insignificant impression overflow as the result of the material detuning. The observed impression overflow leads to inconsiderable ovalization of the section, which is shown by the intensity increase of the material circumferential flow. It is typical of the metal forming rotary methods. During measurement the ovalization of the section is removed, the external spherical surface deviations of forging and the deviations of the hole shape are also reduced.

The shown distribution is characterized by its local concentration at the contact between the tools and the material. The maximum values of reduced stresses are relatively small and do not exceed $\sigma_{H}=120 \mathrm{MPa}$. The largest stresses, which are in contact with tools, are within the external surfaces of the semi-finished product. During the process of compression their range and values are increased. Additionally, they rotate together with the specimen. The larger values of stresses in these areas are due to impression filling by the material and the increased deformation of the material formed by tool. The relatively smaller values of reduced stresses are observed within the internal wall of the hollow forging, and they do not exceed $\sigma_{H}=35 \mathrm{MPa}$. The small values of reduced stresses determined during the numerical simulation enable one to assume that no excessive load of tools takes place during their operation.

Distribution of the formed forging temperature of the hollow forging is related with the strain intensity (Fig. 5). Hence, the maximum values of temperature are within the range of the maximal assumed deformation. The degrees of strain and material flow velocity in the specimen bridges are the largest. Therefore, the temperature here is larger 


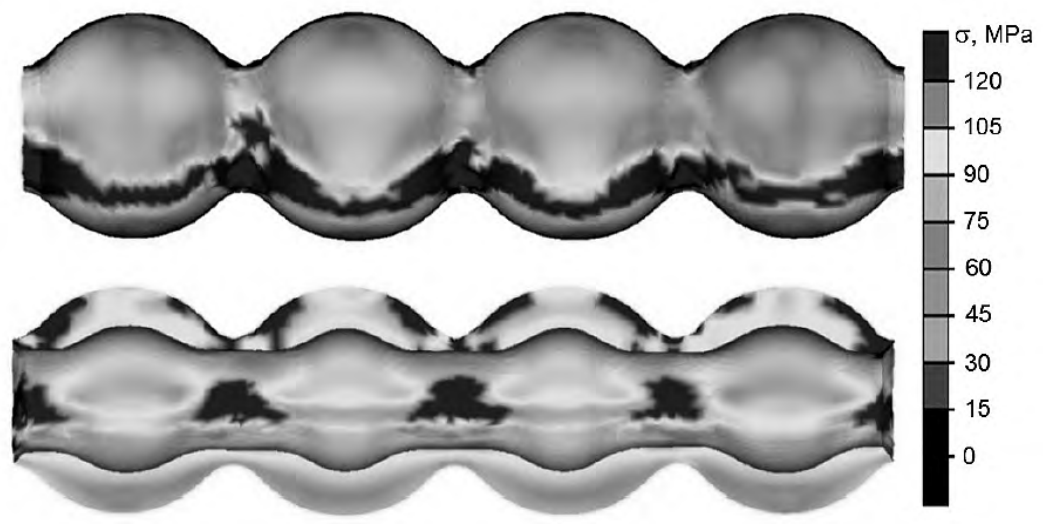

Fig. 4. Distribution of reduced stresses (in MPa) determined numerically in simulations of the rotary compression of the hollow ball specimens at the final stage of compression: (a) on the specimen surface; (b) within the longitudinal section of the specimen.

a

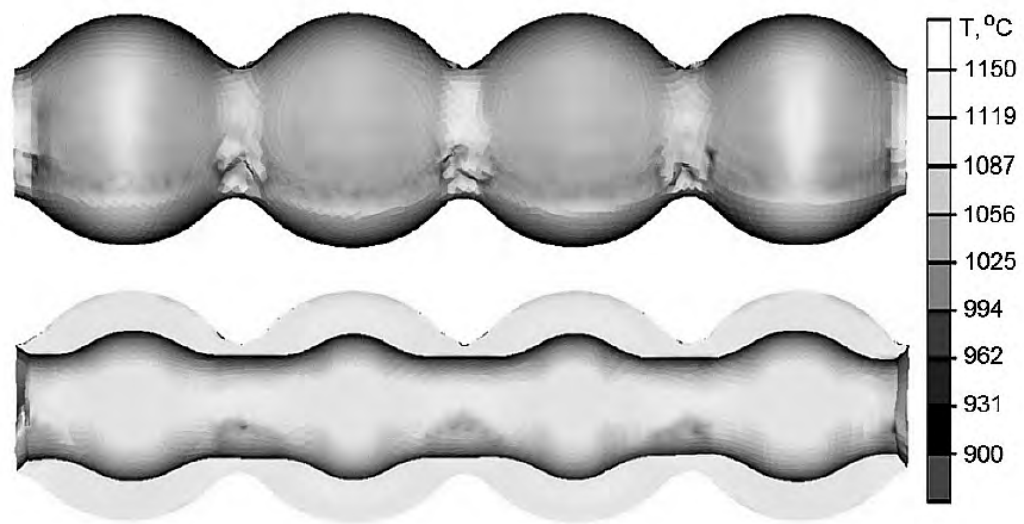

Fig. 5. Temperature distribution (in ${ }^{\circ} \mathrm{C}$ ) determined numerically in compression process simulation for hollow ball specimens at the final stage of compression, (a) at the surface of the formed specimen; (b) within the longitudinal section of the specimen.

compared with that one within the neighboring forging zones. The largest decrease of temperature is on the spherical forging surfaces due to heat transfer to the tools, as well as to the axial internal hole of the forging, where heat exchange with the environment is observed. The rotary compression analysis of the hollow ball forging is observed at the temperature of $1150^{\circ} \mathrm{C}$. At the final stage the temperature is $850^{\circ} \mathrm{C}$. Thus, it can be concluded that the entire process of compression takes place within the scope of one phase, which is required for metal forming processes.

Due to application of the software for simulation of metal forming processes it is possible to analyze the force-energy-related results, which is an integral stage of working out technological process and implies the appropriate choice of tools and technological devices. Figure 6 shows the force and the rotary moment of one of the tools determined by FEM in the rotary compression simulation of the hollow ball forging. At the first stage of the rotary compression, the values of force and rotary moment increase relatively slowly, but constantly up to the maximum. At this stage the tools penetrate into the semi-finished product with a constant velocity, and the area of deformation extends proportionally with the tool travel. The second stage of the specimen compression involves the measurement of the ball-shaped external surfaces. The tools undergo only a rotational motion, the force and the moment decrease relatively rapidly, which means the material deformation reduction. 


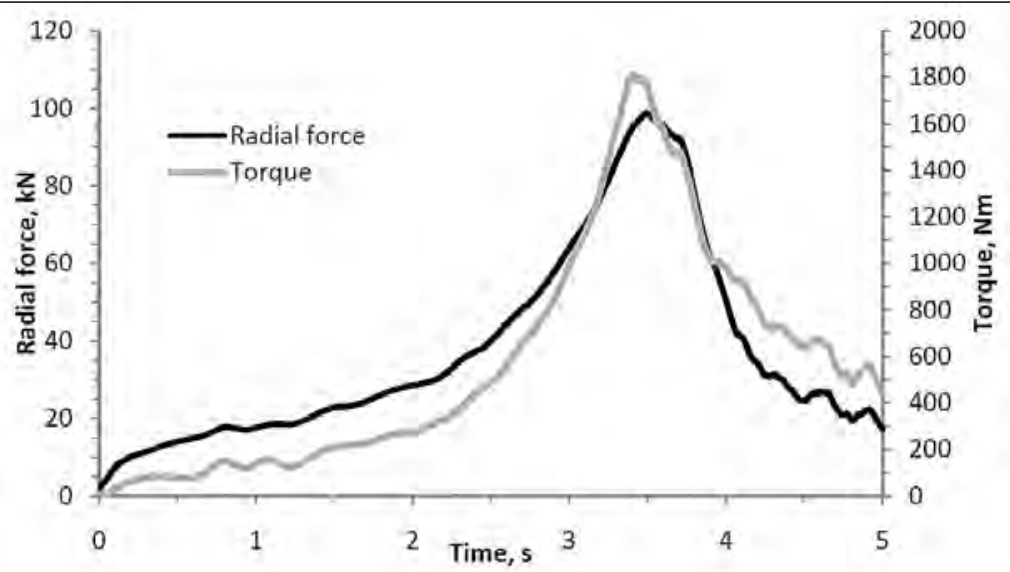

Fig. 6. Rotary moment and force in the compression of hollow ball specimen.

Numerical Simulation Free Formation of Hollow Balls. A relatively wide group of hollow balls represents the elements with a hollow contour of the shape other than circular. In such case, the semi-products of balls can be formed freely (without mandrel). This increases the process stability and decreases the forces and torques. To make the comparison, the numerical simulations of the formation process without mandrel have been performed. The numerical model of the process is identical to that in the earlier analyzed variant, however, the mandrel has been removed from the used billet. Also the kinematic and thermal parameters taken into consideration in the calculations are in the agreement with those assumed during the formation of forging on the mandrel.

The variation of the ball shape determined in the FEM simulations depending on the distribution of strain intensity is shown in Fig. 7. In the analysis of the material flow, a very good agreement between the processes with the mandrel can be observed, especially at the initial stages. Based on the presented data, it can be stated that the lack of the material flow limitation on the inner surface of the billet makes it possible to increase the wall thickness, in comparison with the part with the mandrel.

Moreover, the wall thickness increases not only in the transition zones, but also in the spherical part of the hole. Owing to this fact, it is possible to obtain the spherical shape of the inner ball surface after the hole drilling in the machining. The absence of the internal tool is also reflected by the obtained strain intensity distribution pattern. It is seen that strains (as it observed earlier) concentrate mainly in the neck zones that connect the forgings. However, their maximum values are considerably smaller. It can be explained by the smaller redundant strain occurred in the circumferential direction, which is attributed to a smaller material flow resistance in the radial direction.

The results of the analysis of the thermal parameters of the formed forgings are similar to those ones of the process realized with the mandrel (Fig. 8). Within a large temperature range observed in the formed forgings, the minimal temperatures are exhibited by the superficial layers, which are in contact with the tools, while in the central zone of the material a high temperature remains nearly unchanged, as compared to its initial value. However, noteworthy is the fact that the temperature drop is not large enough to affect the compression process.

As it was predicted, removal of the mandrel allows one to decrease the force parameters, which results in the simplified procedure of the material flow in the radial direction (Fig. 9). Moreover, the character of force and moment is similar to that one obtained from the forgings using the mandrel. At the first stage, the force and the moment increase rapidly due to tools penetration to the material and reduction of the external billet 


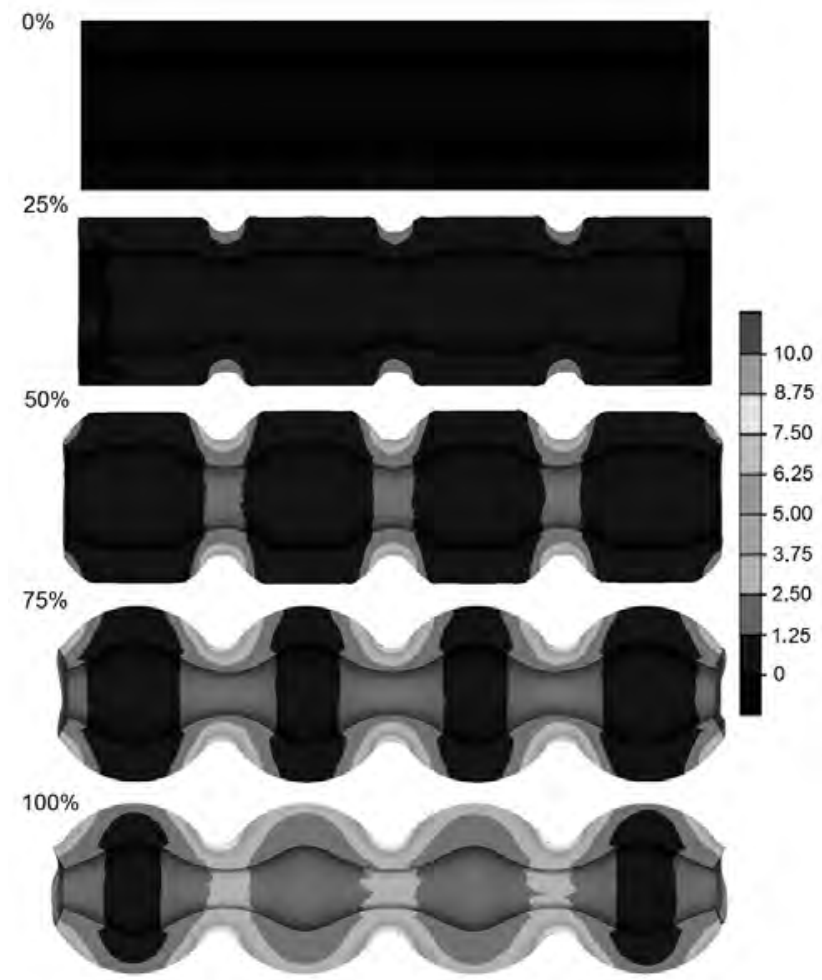

Fig. 7. Determined by FEM shape progression of balls forgings compressed without mandrel with marked distribution of strain intensity.

a
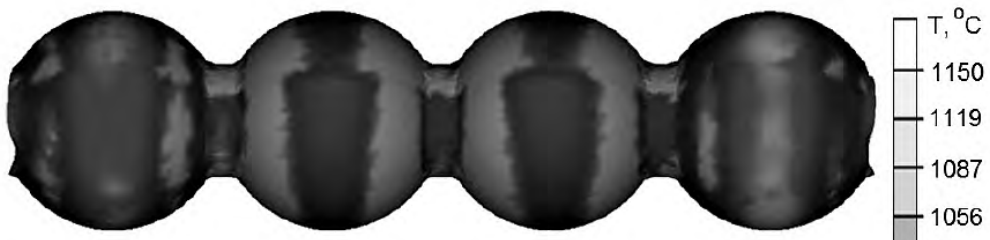

b

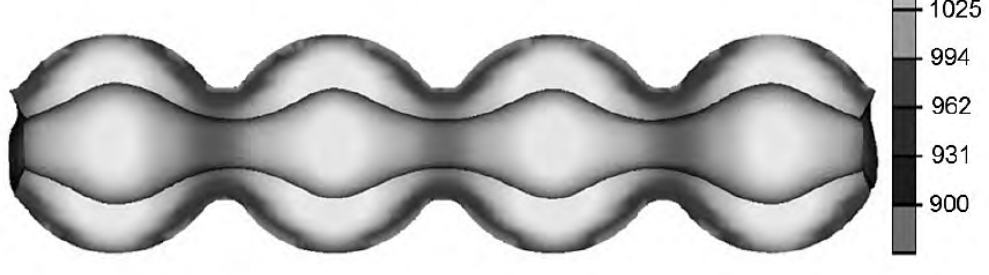

Fig. 8. Temperature distribution at the final stage (in ${ }^{\circ} \mathrm{C}$ ) determined by the numerical simulation of the compression of ball forgings with no mandrel: (a) at the surface; (b) in the longitudinal section.

diameter in the area of bridges connecting the balls. Here, the spherical surfaces of the balls are also formed. Then, during the measurement both the force and the moment rapidly decrease due to elimination of the forging shape inaccuracy without the subsequent reduction of the billet diameter. The comparison between the values of force parameters and those obtained during the process realized with the mandrel is made, and almost $30 \%$ reduction of the maximum values of tools and pressure force of the rotary moment is observed. Smaller forming forces are reflected by the intensity of tool wear, which will be lower for the freely realized processes. Hence, compression process of the mandrel should 


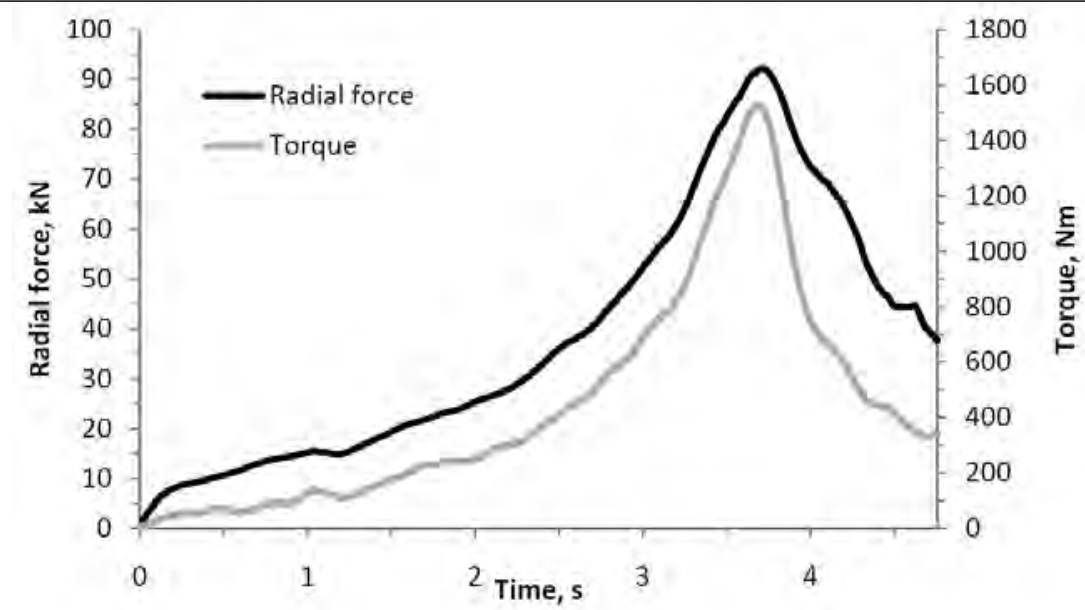

Fig. 9. Force parameters determined in the compression of hollow ball forgings with no mandrel.

be justified by the geometrical requirements for forgings. In case of forging, when the hole shape is insignificant, it is advised to conduct the process with no mandrel.

Initial Experimental Verification of Numerical Results. The initial testing of rotary compression of the hollow ball forging under laboratory conditions is performed to verify the numerical models assumed in the calculations. The tests are conducted in the forging machine for rotary compression at the Lublin University of Technology (Fig. 10). Three sets of the split tools segments are made (Fig. 11), which are placed on the main shafts of the forging machine. The tool includes rollers, on which surface the ring furrows of the compressed balls outline are produced. The billet in the form of the pipe part made of C45 steel with dimensions $\varnothing 38 \times 6 \mathrm{~mm}$ and length $L=140 \mathrm{~mm}$ is used in the compression process. It is heated to the temperature of $1150^{\circ} \mathrm{C}$.

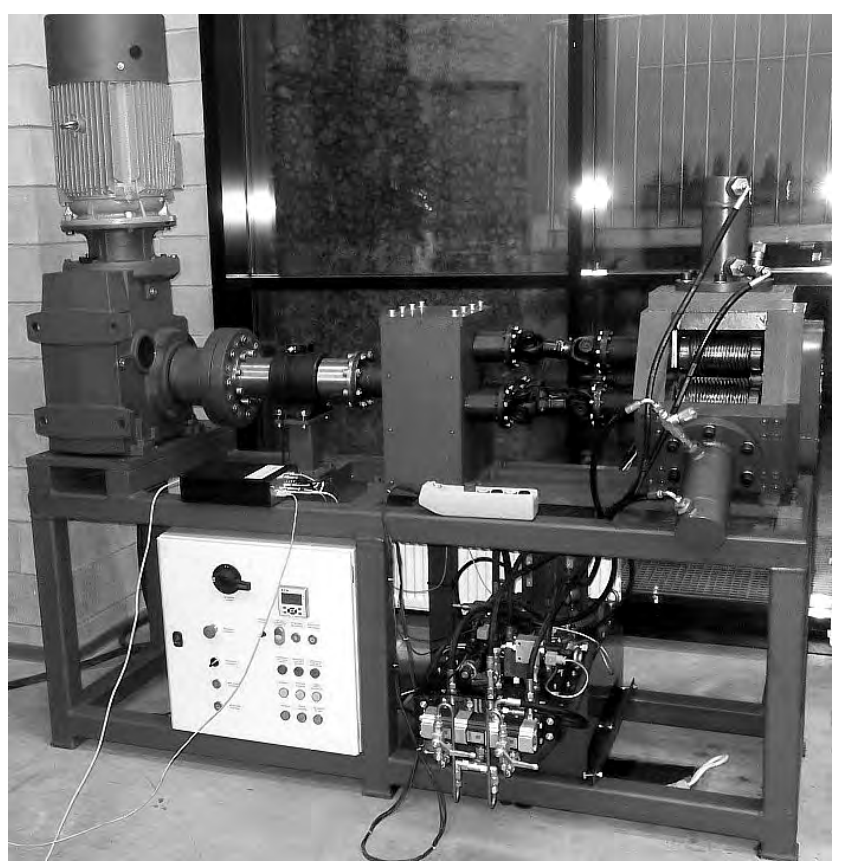

Fig. 10. Forging machine for rotary compression. 


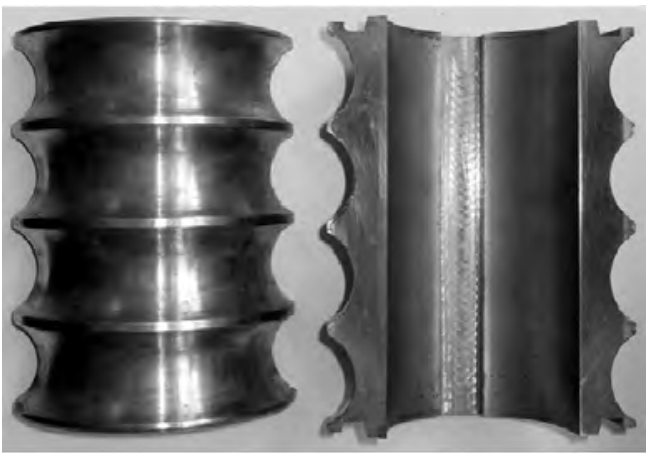

Fig. 11. Set of split tools segments for rotary compression of hollow ball forgings.

Then, the forgings with the kinematic parameters are formed. The rotary velocity of the tools is $n=36 \mathrm{rpm}$, the tool travel velocity is $v=2 \mathrm{~mm} / \mathrm{s}$, the reduction ratio is $\delta=\Delta / \delta=1.9$ (where $D$ is the billet external diameter and $d$ is the external diameter of bridge of the formed forgings).

Figure 12 illustrates the ball forgings formed in the experiment. The elements are connected by the cylindrical necks, which constitute the area of forgings splitting. The obtained semi-finished products exhibit the satisfactory properties of quality and accuracy. The external and the internal surfaces are free from faults. Moreover, there is a good agreement with results obtained in the numerical simulation. This confirms the validity of assumptions used in the numerical simulation.

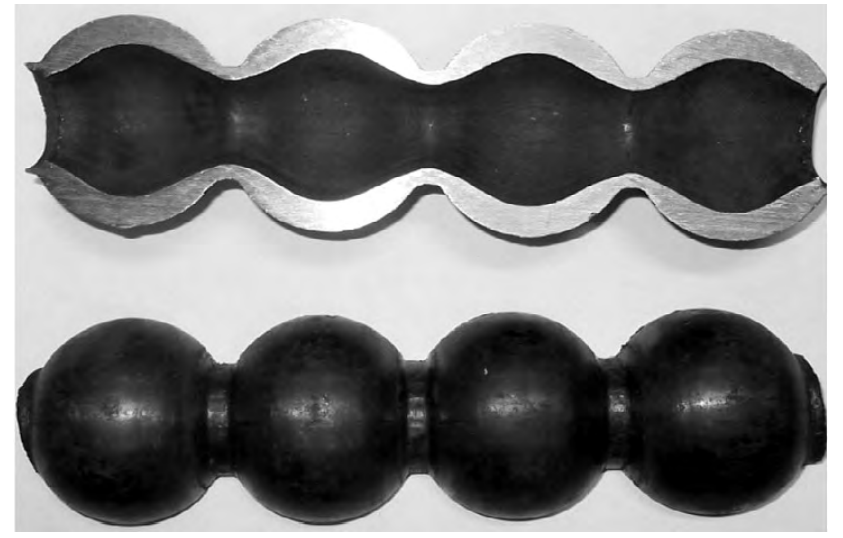

Fig. 12. Balls hollow forgings formed without mandrel during the experiment.

Conclusions. The conducted numerical simulation of the rotary compression of the hollow ball forging under three-dimensional strain conditions considering the thermal analysis made it possible to determine the parameters of force, strain, stress and temperature distribution, as well as to predict the possibilities of the process failure that would make the manufacturing process difficult or impossible. The proposed rotary compression method provides the final products from the billet in the form of the pipe part, due to which fact the material consumption can be reduced in the development of the forging properties. The characteristic feature of the obtained forging is the variation of the wall thickness, which is typical of the rotary compression.

The wall thickness of the semi-finished billet increases gradually from the beginning of the process in the zones of the ball formation, and it is possible to control the radial flow 
of the material due to the use of the mandrel. The rough surface of the external ball forging should be treated as the technological tolerance. The irregular shape of the hole of the obtained specimen does not influence the quality of manufacture of hollow balls.

The results of the performed numerical analysis of the compression of hollow ball forgings confirm the possibility of spherical hollow parts forming. It is recommended to conduct the subsequent investigation to determine the influence of the technological parameters on the quality of the obtained product and factors limiting the rotary compression process applicability.

1. J. Tomczak, Z. Pater, T. Bulzak, "Obciskanie obrotowe dràýonych odkuwek ze stopu magnezu AZ31," Hutnik, Wiadomości Hutnicze, 81, No. 8, 595-599 (2014).

2. J. Tomczak, Z. Pater, T. Bulzak, Obciskanie obrotowe osiowosymetrycznych odkuwek dràýonych, Hutnik, Wiadomości Hutnicze, 81, No. 7, 416-420 (2014).

3. Z. Pater, J. Tomczak, Walcowanie Poprzeczno-Klinowe Kul, Wyd. Politechniki Lubelskiej, Lublin (2012).

4. Z. Pater, J. Tomczak, Walcowanie Śrubowe Kul do Młynów Kulowych, Wyd. Politechniki Lubelskiej, Lublin (2012).

5. G. Winiarski, A. Gontarz, Z. Pater, J. Tomczak, Sposób i Urzqdzenie do Kucia Kul, Polskie zgìoszenie patentowe No. P.403211 (2013).

6. C.-T. Kwan, "A study of process and die design for ball valve forming from stainless steel tube," Int. J. Adv. Manuf. Technol., 26, No. 9, 983-990 (2005).

7. F. Dohmann and Ch. Hartl, "Hydroforming - a method to manufacture light-weight parts," J. Mater. Process. Tech., 60, 669-676 (1996).

8. Y. Zhang, S. Zhao, and Z. Zhang, "Optimization for the forming process parameters of thin-walled valve shell," Thin Wall. Struct., 46, No. 4, 371-379 (2008).

9. F. Schmieder and P. Kettner, "Manufacturing of hollow transmission shafts via bulk-metal forming," J. Mater. Process. Tech., 71, No. 1, 113-118 (1997).

10. Z. Pater, A. Gontarz, J. Tomczak, and T. Bulzak, "Producing hollow drive shaft by rotary compression," Arch. Civ. Mech. Eng., 15, No. 4, 917-924 (2015).

11. J. Tomczak, T. Bulzak, Z. Pater, "Analiza numeryczna ksztaừowania dràýonych odkuwek z uzwojeniami úlimaka," Rudy i Metale Nieýelazne, R60, No. 11, 582-586 (2015). 